Article

\title{
Evaluation of Stone Mastic Asphalt Containing Ceramic Waste Aggregate for Cooling Asphalt Pavement
}

\author{
Qibo Huang ${ }^{1, * \mathbb{D}}$, Zhendong Qian ${ }^{1,2, *}$, Jing $\mathrm{Hu}^{1}$ and Dong Zheng ${ }^{1}$ \\ 1 Intelligent Transportation System Research Center, Southeast University, Nanjing 210096, China; \\ hujing@seu.edu.cn (J.H.); dongzheng_seu@seu.edu.cn (D.Z.) \\ 2 School of Transportation, Southeast University, Nanjing 210096, China \\ * Correspondence: huangqibo@seu.edu.cn (Q.H.); qianzd@seu.edu.cn (Z.Q.)
}

Received: 10 June 2020; Accepted: 29 June 2020; Published: 2 July 2020

check for updates

\begin{abstract}
Construction and demolition waste material is of great potential for use in pavement engineering. This paper aims to investigate the feasibility of ceramic waste aggregate (CA) used in cooling asphalt pavement through a series of test methods and simulation techniques. Stone mastic asphalt (SMA) containing 10\%, 20\%, 30\%, 40\%, and 50\% coarse ceramic waste aggregate (CASMAs) was first designed using the Marshall method. Afterward, the road performance and thermal insulation performance of the five different CASMAs were assessed by a comprehensive lab test, including a wheel rutting test, moisture susceptibility test, bending beam test, fatigue beam test, and indoor thermal insulation test. Finally, a 2D finite-element (FE) model was developed to investigate the transient thermal field and rutting deformation response of the cooling asphalt pavement with CASMAs. Results show that CASMAs experienced degradation of rutting resistance, moisture susceptibility, and anti-cracking performance while still meeting technical requirements with CA content of up to $40 \%$. On the other hand, CASMAs can cool the pavement's temperature by $11.5^{\circ} \mathrm{C}$ at the bottom of asphalt layers. The permanent rutting deformation of cooling asphalt pavement was $45.36 \%$ smaller than that of conventional asphalt pavement without CASMAs. Based on the test results and numerical simulation results, the optimum content of ceramic waste aggregate in stone mastic asphalt was recommended as $40 \%$.
\end{abstract}

Keywords: cooling asphalt pavement; SMA; ceramic waste aggregate; road performance; thermal insulation performance; transient thermal field; rutting deformation

\section{Introduction}

Asphalt pavement is one of the most widely applied transportation methods for passengers due to its high evenness, comfort, and low noise [1]. With the high solar heat absorptivity of asphalt, this black pavement usually suffers an extraordinary increase in structural temperature on hot days [2]. When subjected to both heavy traffic load and high temperature, this black pavement faces a high risk of rutting deformation because of the viscous flow of asphalt mixture. Moreover, asphalt pavement is liable to store and radiate a large amount of heat energy, leading to an exacerbation of the urban heat island (UHI) effect [3]. Therefore, there is a trend for urban traffic to require cooler and tougher asphalt pavement.

With the aim of dealing with the rutting problem of asphalt pavement, most efforts have been devoted to modifying the asphalt binder, adjusting aggregate gradation, and incorporating anti-rutting agents [4-7]. Some attention has also been paid to improving anti-rutting performance by lowering the structural temperature. Anting et al. [8] used three types of waste tile aggregate to develop a coating 
material for asphalt pavement. The surface temperature detected was performed at actual tropical weather climate and the results showed that a coating material with porcelain can obtain the largest surface temperature reduction of up to $6.4^{\circ} \mathrm{C}$. Synnefa et al. [9] conducted laboratory tests on the thermal performance of five thin colored layers of asphalt and performed a thermal fluid dynamics simulation of those samples on roads. It was found that a thin layer of colored asphalt can lower surface temperatures by as much as $10^{\circ} \mathrm{C}$ compared with black asphalt. Jiang et al. [10] performed a series of tests to investigate the cooling effect, rutting resistance performance, and durability of thermally resistant course, heat-reflective coating, and thermally resistant and heat-reflective coating integrated pavement. It was concluded that thermally resistant and heat-reflective coating integrated pavement showed the best performance. Wang et al. [11] compared the cooling effect of different thermal-resistant aggregates on the asphalt mixture. Since the temperature of the thermal-resistant concrete drops rapidly over time, it was inferred that using thermal-resistant aggregate had an obvious cooling effect on the asphalt mixture.

On the other hand, the construction industry has constantly been producing large quantities of residue over the past decades [12,13]. Most of this residue is generated from construction and demolition, and mainly consists of concrete debris, cement mortar debris, and crushed ceramic $[14,15]$. Crushed ceramic is light in color and has a low thermal conductivity; it may help to reduce asphalt pavement's storage of heat energy and lower the temperature of asphalt pavement. Therefore, the utilization of crushed ceramic waste in asphalt pavement is of great potential for controlling rutting defects, alleviating the UHI effect, and recycling solid waste.

Since using ceramic waste to replace natural aggregates may have considerable economic and environmental values, the limited research published has mainly focused on the feasibility of using ceramic waste in asphalt mixture. Hussein et al. [16] ground ceramic source waste to generate a nano ceramic powder (NCP) and investigated properties of bitumen modified by NCP. It was confirmed by the Asphalt Pavement Analyzer (APA) result that the rutting resistance of asphalt mixture was highly improved by the NCP. Muniandy et al. [17] conducted a comparative analysis of the chemical composition, particle size, morphology, and density of ceramic waste filler. It was concluded that the ceramic waste filler met the technical requirements for pavement use, and that asphalt mixture containing ceramic waste filler had better performance in rutting resistance compared to asphalt mixture with natural filler. Van De Ven et al. [18] analyzed the effect of coarse ceramic waste aggregate (CA) on the road performance of asphalt mixture. The test result showed that the addition of CA could improve the indirect tensile (IDT) strength, dynamic modulus, and fatigue life of asphalt mixture, but could impair the water stability of asphalt concrete. Ramón Silvestre et al. [19] concluded that using CA can increase the optimal asphalt content (OAC) and the air void of asphalt concrete, and asphalt mixture containing CA is recommended for roads with medium traffic. In summary, the evolution of performance during the service life of CASMAs has differences from that of conventional asphalt mixture, and little research has been carried out on both the cooling effect and the anti-rutting effect of CA on asphalt mixture. Therefore, further investigation of using ceramic waste aggregate in cooling asphalt pavement is still necessary.

\section{Research Objective and Approach}

This paper mainly focuses on exploring the feasibility of ceramic waste aggregate used as a substitution for natural aggregate in asphalt mixture. Understanding the impact of ceramic waste aggregate on road performance and the thermal insulation characteristic of asphalt mixture can help to deal with rutting defects, ease the heat island effect, and consume solid waste. To that end, a series of tests and simulations were performed to evaluate the cooling effect and anti-rutting deformation performance of asphalt mixture containing ceramic waste. A flow chart of the research approach is shown in Figure 1. 


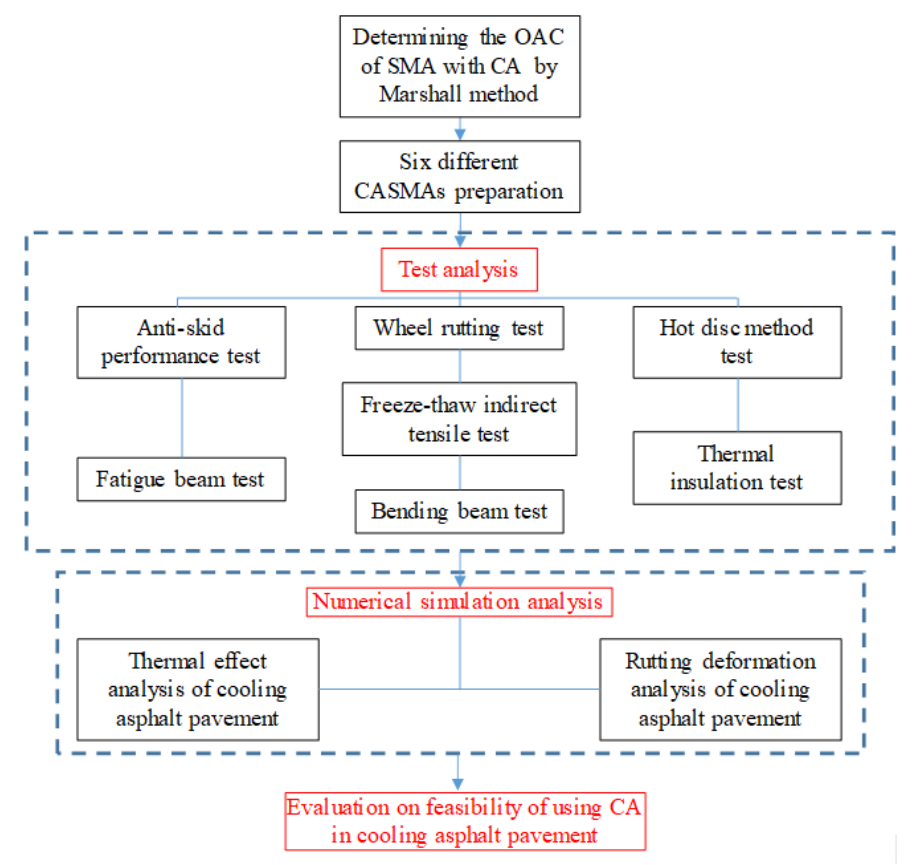

Figure 1. Flow chart of the research approach.

\section{Materials and Methods}

\subsection{Materials and Specimen Preparation}

Stone mastic asphalt with gap gradation has a larger amount of coarse aggregate than conventional asphalt mixture with continuous gradation. More ceramic waste aggregate with small thermal conductivity can be used to replace natural coarse aggregates in stone mastic asphalt (SMA), which makes the thermal insulation performance of the asphalt mixture more significant. Therefore, this paper selected stone mastic asphalt (SMA) for the follow-up research.

\subsubsection{Aggregate and Filler}

There are different types of ceramic waste, such as daily-use ceramics, bathroom ceramics, ceramic tiles, and insulating ceramics. The ceramic waste used in this paper was derived from waste ceramic tiles from the demolition of buildings, which belongs to the category of construction solid waste.

The collected ceramic was washed, dried, crushed with a jaw crusher, sieved in a dry way, and stored in sizes of 5/10,10/13, and 13/16 mm for the later preparation of the asphalt mixture. Natural basalt coarse aggregate was used as a control with a nominal maximum size of $13.2 \mathrm{~mm}$. In addition, the fine aggregate used in the asphalt mixture was natural basalt, while the filler used was limestone. The fiber used in the stone mastic asphalt was lignin fiber. The morphologies of basalt aggregate and CA are shown in Figure 2.

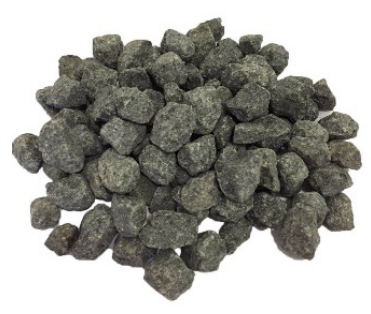

(a)

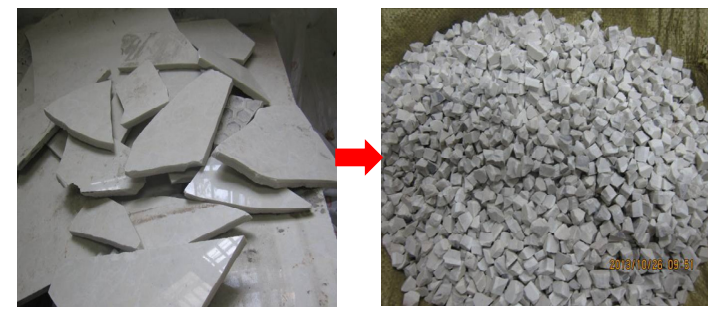

(b)

Figure 2. Aggregate used in this study: (a) Basalt aggregate; (b) Crushed ceramic waste aggregate. 
The physical properties of aggregate and filler used are listed in Table 1. It was confirmed that the ceramic waste aggregate meet most specification values of the Superpave ${ }^{\mathrm{TM}}$ Aggregate Specification Tests except for the index of flat and elongated particle content. As seen in Table 1, the density of ceramic waste aggregate is smaller than basalt, and this is mainly due to the large amount of micro-pore generated during the firing of ceramics. Aggregate with a porous structure can lower the heat absorption capacity of the asphalt mixture and reduce the heat transfer efficiency inside the pavement structure [11]. However, the crushing value and Los Angeles abrasion of ceramic waste aggregate (CA) are much higher than those of basalt aggregate. The main reason is that the ceramic tile is a more brittle material compared with natural aggregate, and it is easier to suffer brittle failure under the action of pressure and impact force.

Table 1. Physical properties of aggregate and filler used in this study.

\begin{tabular}{|c|c|c|c|c|}
\hline Technical Indices & Aggregate/Filler & Measure Value & Test Method & Criteria \\
\hline Crushing value/\% & $\begin{array}{c}\text { CA } \\
\text { Basalt aggregate }\end{array}$ & $\begin{array}{l}22.7 \\
10.6\end{array}$ & BS 812-110 [20] & Maximum of 35 \\
\hline Los Angeles abrasion $/ \%$ & $\begin{array}{c}\text { CA } \\
\text { Basalt aggregate }\end{array}$ & $\begin{array}{l}20.5 \\
11.4\end{array}$ & ASTM C131 [21] & Maximum of 40 \\
\hline $\begin{array}{l}\text { Flat and elongated particle } \\
\text { content } / \%\end{array}$ & $\begin{array}{c}\mathrm{CA} \\
\text { Basalt aggregate }\end{array}$ & $\begin{array}{c}13.8 \\
2.6\end{array}$ & ASTM D4791 [22] & Maximum of 10 \\
\hline Water absorption rate $/ \%$ & $\begin{array}{c}\text { CA } \\
\text { Basalt aggregate }\end{array}$ & $\begin{array}{l}0.86 \\
0.32\end{array}$ & ASTM C127 [23] & None \\
\hline Density $/ \mathrm{g} \cdot \mathrm{cm}^{-3}$ & $\begin{array}{l}\text { CA } \\
\text { Basalt aggregate } \\
\text { Limestone filler }\end{array}$ & $\begin{array}{l}2.348 \\
2.941 \\
2.723\end{array}$ & $\begin{array}{l}\text { ASTM C127 [23] } \\
\text { ASTM C128 [24] }\end{array}$ & None \\
\hline Plasticity index & Limestone filler & Non-plastic & ASTM D4318 [25] & Non-plastic \\
\hline
\end{tabular}

\subsubsection{Asphalt Binder}

To keep the stone mastic asphalt containing CA from cracking, rutting, and moisture damage, the asphalt binder used should have robust anti-aging performance, high viscosity, and good adhesion with the aggregate. The asphalt binder selected was Styrene butadiene styrene block polymer (SBS) modified asphalt, and its main technical indices are shown in Table 2.

Table 2. Basic properties of SBS modified asphalt.

\begin{tabular}{cccc}
\hline Technical Indices & Measure Value & Test Method & Criteria \\
\hline Penetration at $25{ }^{\circ} \mathrm{C} / 0.1 \mathrm{~mm}$ & 63.4 & ASTM D5 [26] & $50-70$ \\
Softening point $/{ }^{\circ} \mathrm{C}$ & 72.0 & ASTM D36 [27] & $\geq 60$ \\
Ductility at $5{ }^{\circ} \mathrm{C} / \mathrm{cm}$ & 78.5 & ASTM D113 [28] & $\geq 30$ \\
Solubility in trichloroethylene/\% & 99.4 & ASTM D2042 [29] & $\geq 99$ \\
Flash point $/{ }^{\circ} \mathrm{C}$ & 260 & ASTM D92 [30] & $\geq 230$ \\
Viscosity at $135{ }^{\circ} \mathrm{C} / \mathrm{Pa} \cdot \mathrm{s}$ & 2.16 & ASTM D2170 [31] & $\geq 3$ \\
Elastic recovery $\%$ & 94 & ASTM D113 [28] & $\geq 99$ \\
After the Rolling Thin Film Oven Test (RTFOT) & $\geq 1.0$ \\
Loss in weight $/ \%$ & 0.12 & ASTM D1754 [32] & $\geq 70$ \\
Retained penetration/\% & 64 & ASTM D5 [26] & $\geq 20$ \\
Ductility at $5{ }^{\circ} \mathrm{C} / \mathrm{cm}$ & 28 & ASTM D113 [28]
\end{tabular}

\subsubsection{Mix Design}

To ensure the comparability of test results, the gradations of stone mastic asphalt with coarse CA and coarse basalt aggregate were kept the same, and the synthetic gradation was selected according to JTG F40-2004 [33], as shown in Figure 3. 


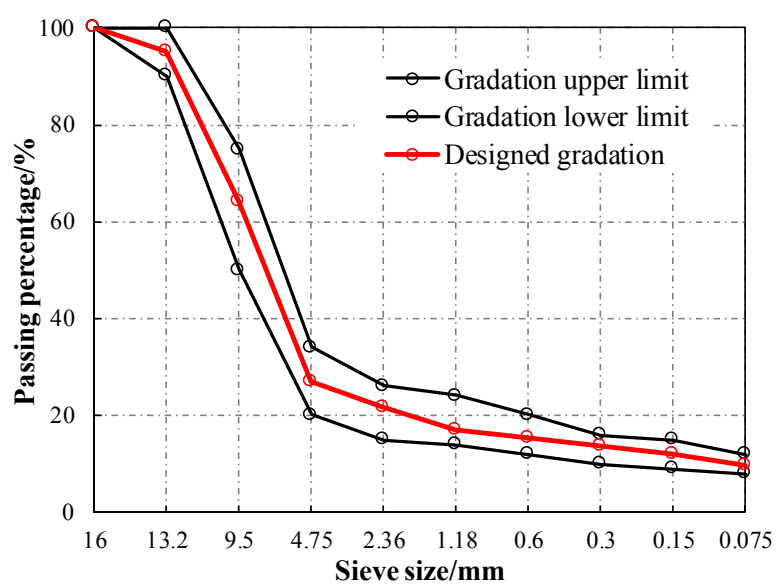

Figure 3. Designed gradation of CASMA-13 and SMA-13.

The particle sizes of ceramic waste aggregate were 5/10, 10/13, and 13/16 mm. Meanwhile, according to Figure 3, the volume ratios of basalt aggregates with particle sizes of 5/10 mm, 10/13 $\mathrm{mm}$, and $13 / 16 \mathrm{~mm}$ were $37.2 \%, 31.1 \%$, and $4.5 \%$, respectively. As a result, specimens were prepared with different replacement percentages of ceramic waste aggregate $(10 \%, 20 \%, 30 \%, 40 \%$, and $50 \%$ by volume) blended with basalt aggregate. The aggregate was preheated at $190^{\circ} \mathrm{C}$, the mixing temperature of stone mastic asphalt was $175^{\circ} \mathrm{C}$, and the compaction temperature of stone mastic asphalt was $160^{\circ} \mathrm{C}$. Fifty blows of a Marshall hammer were applied on each side during the preparation of specimens.

With the incorporation of ceramic waste aggregate, the optimum asphalt content (OAC) of the stone mastic asphalt changed accordingly. Therefore, it was necessary to determine the OAC of stone mastic asphalt with different amounts of ceramic waste aggregate. According to JTG F40-2004, the OAC of SMA is determined using the air void acquired by the Marshall design method, and aggregate void in asphalt mixture filled with asphalt (VFA), void in mineral aggregate in asphalt mixture (VMA), Marshall stability, flow value, leakage loss value, and scattering loss values are used to validate the adequacy of SMA's OAC. Based on a target porosity of $4.0 \%$, the OACs of SMA-13, CASMA-13 $(10 \%)$, CASMA-13 (20\%), CASMA-13 (30\%), CASMA-13 (40\%), and CASMA-13 (50\%) were determined as $5.7 \%, 5.8 \% .5 .9 \%, 6.0 \%$, and $6.2 \%$, respectively. The Marshall test results of stone mastic asphalt with optimum asphalt content are shown in Table 3.

Table 3. Marshall test results of stone mastic asphalt containing CA.

\begin{tabular}{|c|c|c|c|c|c|c|c|}
\hline \multirow{2}{*}{ Index } & \multirow{2}{*}{ SMA-13 } & \multicolumn{5}{|c|}{ CASMA-13 } & \multirow{2}{*}{ Criteria } \\
\hline & & $10 \%$ & $20 \%$ & $30 \%$ & $40 \%$ & $50 \%$ & \\
\hline Optimum asphalt content $/ \%$ & 5.7 & 5.8 & 5.8 & 5.9 & 6.0 & 6.2 & - \\
\hline Density $/ \mathrm{g} \cdot \mathrm{cm}^{-3}$ & 2.520 & 2.493 & 2.479 & 2.438 & 2.418 & 2.362 & - \\
\hline Air void $/ \%$ & 4.0 & 3.9 & 3.8 & 3.9 & 4.0 & 3.9 & $3.0-4.0$ \\
\hline VFA/\% & 78.1 & 78.6 & 80.2 & 78.40 & 79.21 & 81.22 & $75-85$ \\
\hline VMA/\% & 17.3 & 17.3 & 17.1 & 16.9 & 17.4 & 17.0 & $\geq 17$ \\
\hline Stability/kN & 8.65 & 7.39 & 7.36 & 7.28 & 7.13 & 6.57 & $\geq 6.0$ \\
\hline Flow value/ $0.1 \mathrm{~mm}$ & 20.8 & 21.0 & 23.5 & 22.8 & 25.61 & 28.37 & $20-50$ \\
\hline Leakage loss/\% & 0.05 & 0.06 & 0.06 & 0.07 & 0.09 & 0.12 & $\geq 0.1$ \\
\hline Scattering loss $/ \%$ & 3.5 & 5.5 & 5.8 & 7.3 & 11.5 & 13.2 & $\geq 15$ \\
\hline
\end{tabular}

The increasing OAC of CASMA-13 occurred mainly because ceramic waste aggregate has a higher water absorption than that of basalt aggregate. Secondly, the Marshall stability of stone mastic asphalt greatly decreased with the incorporation of ceramic waste aggregate, while the flow value increased. Moreover, the leakage loss value and scattering loss value of stone mastic asphalt both increased with the increase of ceramic waste aggregate. When the incorporation of ceramic waste aggregate was 
$50 \%$, the leakage loss value exceeded the maximum specification value of $0.1 \%$. This was mainly due to the poor adhesion of asphalt and ceramic waste aggregate, resulting in more free asphalt. In summary, the overall performance of stone mastic asphalt containing CA weakened as the ceramic waste aggregate increased, so the amount of CA in asphalt mixture should be limited.

\subsection{Experimental Methods}

Compared with conventional stone mastic asphalt (SMA-13), the road performance of CASMAs considering different ceramic waste aggregate content was assessed by carrying out an experimental program as follows: (a) a wheel rutting test to evaluate permanent deformation resistance; (b) a freeze-thaw indirect tensile test to assess moisture susceptibility at the freeze-thaw condition; (c) a three-point bending beam test to investigate resistance to cracking at low temperature; (d) a thermo-physical parameter test; (e) a mean texture depth (MTD) test and a British pendulum number (BPN) test to assess the skidding resistance of CASMAs; (f) a three-point fatigue beam test to study the fatigue resistance of CASMAs; $(\mathrm{g})$ a thermal insulation test to investigate the insulation effect of CASMAs' surface course. Table 4 lists the whole experimental program.

Table 4. Test arrangement.

\begin{tabular}{|c|c|c|c|c|}
\hline Test & Property & Material & Index & Test Method \\
\hline Wheel rutting test & $\begin{array}{l}\text { Deformation } \\
\text { resistance }\end{array}$ & \multirow{6}{*}{$\begin{array}{c}\text { SMA-13 }(0 \%), \\
\text { CASMA-13 }(10 \%), \\
\text { CASMA-13 }(20 \%), \\
\text { CASMA-13 }(30 \%), \\
\text { CASMA-13 }(40 \%), \\
\text { CASMA-13 }(50 \%) .\end{array}$} & Dynamic stability & JTG E20-2011 T0719 [34] \\
\hline $\begin{array}{l}\text { Freeze-thaw indirect } \\
\text { tensile test }\end{array}$ & $\begin{array}{c}\text { Moisture } \\
\text { susceptibility }\end{array}$ & & $\begin{array}{l}\text { Tensile strength } \\
\text { ratio (TSR) }\end{array}$ & AASHTO T283 [29] \\
\hline Bending beam test & Cracking resistance & & Bending strength & JTG E20-2011 T0715 [34] \\
\hline $\begin{array}{l}\text { Thermophysical parameter } \\
\text { test (hot disc method test) }\end{array}$ & $\begin{array}{l}\text { Thermophysical } \\
\text { performance }\end{array}$ & & $\begin{array}{c}\text { Conductivity } \\
\text { Diffusivity } \\
\text { Specific heat }\end{array}$ & ASTM WK49591 [35] \\
\hline \multirow[t]{2}{*}{ Anti-skid performance test } & \multirow{2}{*}{$\begin{array}{l}\text { Anti-skid } \\
\text { performance }\end{array}$} & & $\begin{array}{l}\text { British pendulum } \\
\text { number (BPN) }\end{array}$ & ASTM E303 [36] \\
\hline & & & $\begin{array}{l}\text { Mean texture depth } \\
\text { (MTD) }\end{array}$ & ASTM E965 [37] \\
\hline Fatigue beam test & $\begin{array}{l}\text { Fatigue } \\
\text { performance }\end{array}$ & & Failure cycles & CEN-EN 12697-24 [38] \\
\hline Thermal insulation test & $\begin{array}{l}\text { Thermal insulation } \\
\text { performance }\end{array}$ & & $\begin{array}{l}\text { Temperature } \\
\text { difference }\end{array}$ & Designed in this study \\
\hline
\end{tabular}

\subsubsection{Wheel Rutting Test}

Slab specimens were manufactured by a roller compaction device. Aggregates and SBS modified asphalt were first mixed thoroughly at $175^{\circ} \mathrm{C}$. Then the filler was incorporated for the following mixing. Finally, mixtures were compacted under the roller at $160{ }^{\circ} \mathrm{C}$ to obtain a slab specimen $(300 \mathrm{~mm}$ $\times 300 \mathrm{~mm} \times 50 \mathrm{~mm}$ ).

The wheel rutting test was carried out based on a procedure in the Chinese test specifications JTG E20-2011 T0719. During the test, a rubber wheel was subjected to the slab specimen, as presented in Figure 4a. The contact pressure was $0.70 \mathrm{MPa}$, and the temperature was $60^{\circ} \mathrm{C}$ for the entire test. Linear variable differential transformers (LVDTs) were utilized to record the vertical deformation of the slab specimen during the test. Dynamic stability (DS) means the number of wheel passes required to beget one millimeter of rut deformation and can be calculated by Equation (1):

$$
D S=C_{1} \times C_{2} \frac{\left(t_{2}-t_{1}\right) N}{d_{2}-d_{1}}
$$

where $t_{1}$ is $45 \mathrm{~min}$ and $t_{2}$ is $60 \mathrm{~min} ; d_{1}$ and $d_{2}$ are the corresponding rut deformations; $C_{1}$ and $C_{2}$ are specific parameters of the wheel rutting tester and asphalt mixture type, here $C_{1}=1, C_{2}=1 ; N$ is the passing speed of the rubber wheel, here $N=42$ passes $\cdot \mathrm{min}^{-1}$. 

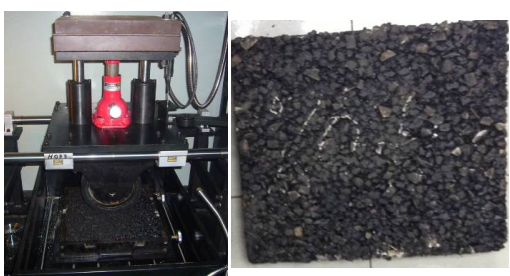

(a)
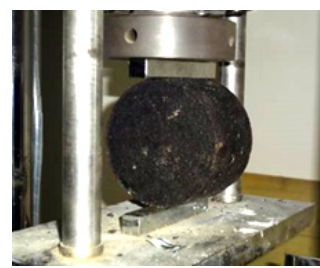

(b)

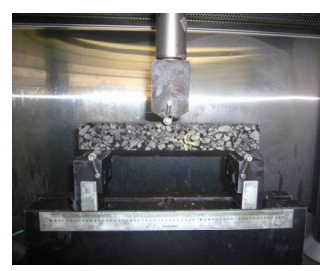

(c)

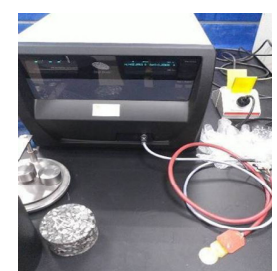

(d)

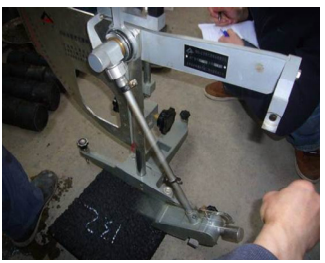

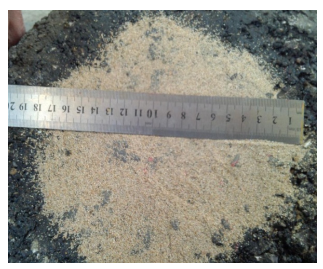

(e)
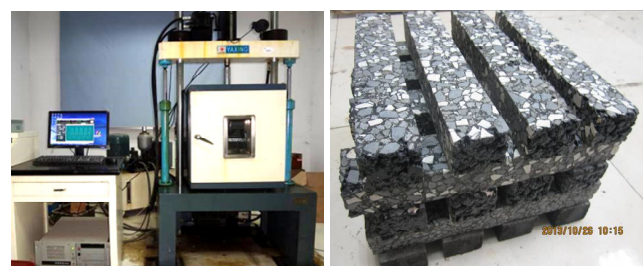

(f)
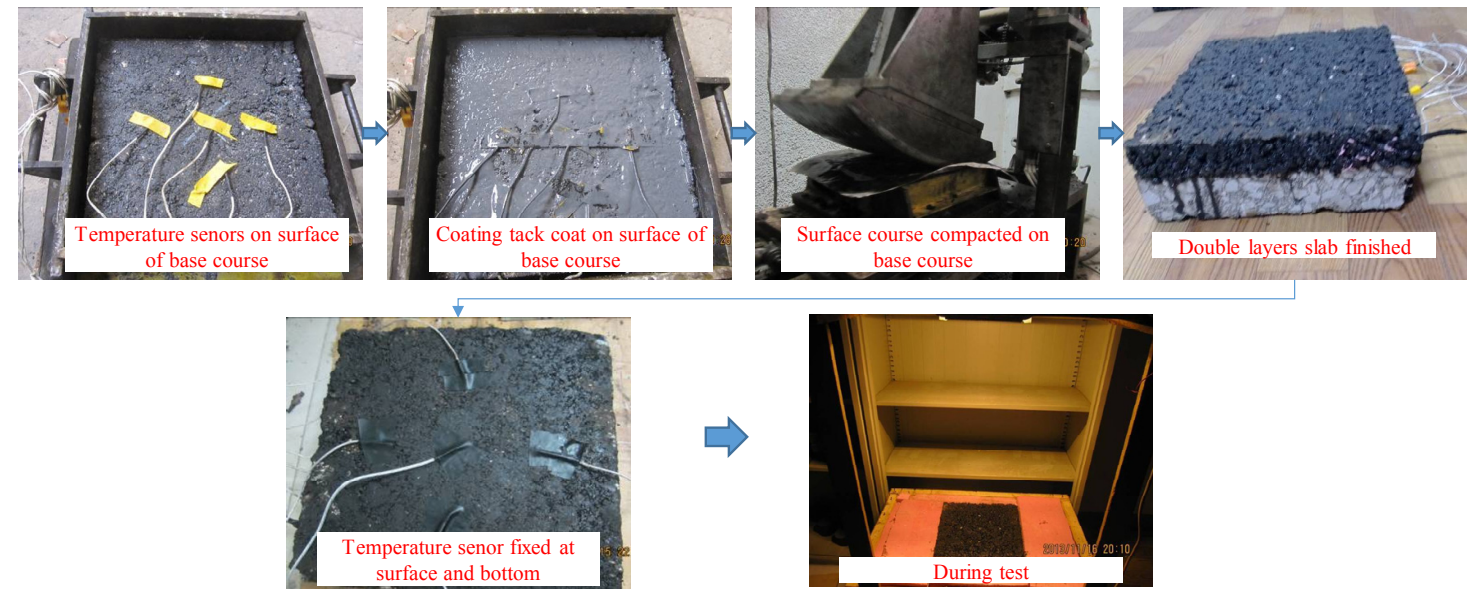

(g)

Figure 4. Test methods: (a) Wheel rutting test; (b) Freeze-thaw indirect tensile test; (c) Bending beam test; (d) HDM test; (e) Anti-skid performance test; (f) Fatigue beam test; (g) Thermal insulation performance test.

\subsubsection{Freeze-Thaw Indirect Tensile Test}

A freeze-thaw indirect tensile test was conducted to assess the moisture susceptibility of CASMAs at freeze-thaw conditions, following a procedure in AASHTO T283. During the test, four Marshall specimens were placed in a $25{ }^{\circ} \mathrm{C}$ water bath for $2 \mathrm{~h}$ as an unconditioned group. The other four Marshall specimens were placed in a $25^{\circ} \mathrm{C}$ water bath for $2 \mathrm{~h}$, then conditioned for one freeze-thaw cycle. During the freeze-thaw cycle, the Marshall specimens were immersed in water under vacuum state for $15 \mathrm{~min}$, then frozen at $-18^{\circ} \mathrm{C}$ in a refrigerator for $16 \mathrm{~h}$, and then immersed in $60{ }^{\circ} \mathrm{C}$ water for $24 \mathrm{~h}$. Finally, the indirect tensile strength (ITS) of the specimen was measured by a mechanical testing and simulation system (MTS) with a load rate of $50 \mathrm{~mm} / \mathrm{min}$ at ambient temperature, as shown in Figure $4 \mathrm{~b}$. The tensile strength ratio (TSR) of CASMAs was defined by the ratio of ITS conditioned to unconditioned.

\subsubsection{Bending Beam Test}

A three-point bending beam test was conducted to characterize the low-temperature cracking resistance of CASMA-13 following the procedure in JTG E20-2011 T0715. The rolling compacted slab specimen $(300 \mathrm{~mm} \times 300 \mathrm{~mm} \times 50 \mathrm{~mm}$ ) was cut into beam specimens with a size of $250 \mathrm{~mm}$ in length, 
$30 \mathrm{~mm}$ in width, and $35 \mathrm{~mm}$ in height. The beam specimens were then tested using a universal testing machine system (UTM-25, IPC, Melbourne, Victoria, Australia) with a load rate of $50 \mathrm{~mm} / \mathrm{min}$ at $-10^{\circ} \mathrm{C}$, as shown in Figure $4 \mathrm{c}$.

\subsubsection{Hot Disc Method Test}

CASMAs are expected to lower the temperature of the pavement structure. The thermo-physical parameters were measured by a hot disc method (HDM) test, according to the procedure in ASTM WK49591. The gyratory compacted cylinder specimen $(\Phi 150 \mathrm{~mm} \times \mathrm{H} 120 \mathrm{~mm})$ was drilled and cut into a smaller cylinder specimen $(\Phi 100 \mathrm{~mm} \times \mathrm{H} 100 \mathrm{~mm})$ to ensure that the surface was smooth enough for the hot disc method test. The test was performed on the cylinder specimen at $20{ }^{\circ} \mathrm{C}$, and the external heat source for the specimen was simulated by the hot disc probe. In addition, the temperature evolution of specimen was measured by the hot disk probe, as shown in Figure $4 \mathrm{~d}$. The thermal conductivity, thermal diffusivity, and specific heat were calculated by the transient plane source method [39].

\subsubsection{Anti-Skid Performance Test}

The anti-skid performance was assessed by indices of mean texture depth (MTD) and British pendulum number (BPN). The sand patch method test outlined in ASTM E965 was employed to measure the MTD, and the British pendulum test described in ASTM E303 was used to measure the BPN. Both of these two tests were carried out on the slab specimen ( $300 \mathrm{~mm} \times 300 \mathrm{~mm} \times 50 \mathrm{~mm})$, as shown in Figure 4e.

\subsubsection{Fatigue Beam Test}

Asphalt pavement is subjected to numerous repetitions of wheel loads and environmental conditions. Therefore, the materials used in asphalt pavement should have a great fatigue resistance performance to resist the generation of cracks in the pavement. In this study, the fatigue performance of CASMAs was assessed by a three-point bending beam test at $20^{\circ} \mathrm{C}$ following the procedure in European Standard EN 12697-24, as shown in Figure 4f. The rolling compacted slab specimen was cut into beam specimens with a size of $300 \mathrm{~mm}$ in length, $40 \mathrm{~mm}$ in width, and $50 \mathrm{~mm}$ in height. Then the fatigue beam test was performed on these beam specimens. The load control mode with a half-sine waveform of $10 \mathrm{~Hz}$ frequency was selected to simulate the wheel load on the pavement, and the stress ratio was chosen as $0.6,0.5,0.4$, and 0.3 [40]. In this paper, the fatigue life of stone mastic asphalt was defined as the number of load cycles required for a 50\% reduction of the beam specimen's initial stiffness.

\subsubsection{Thermal Insulation Test}

An indoor thermal insulation test was designed as shown in Figure 5. A tungsten iodine lamp with a power of $500 \mathrm{~W}$ was used to simulate solar radiation.

A double-layer slab specimen with a $4 \mathrm{~cm}$ surface course and a $6 \mathrm{~cm}$ base course (AC-20) was fabricated, and the temperatures of the surface, interface, and bottom were recorded through a thermocouple thermometer. The AC-20 mixture with a continuous gradation was made of limestone coarse aggregate, basalt fine aggregate, limestone filler, and SBS modified asphalt. Figure $4 \mathrm{~g}$ shows the fabrication procedure of the composite specimen. The height of the liftable floor was adjusted to ensure that the lamp's illuminance on the specimen's surface was 140,000 1x [41]. Conventional stone mastic asphalt (SMA-13) was used as a control group to compare the thermal insulation effect of CASMAs. Additionally, the composite specimen was under radiant heating for $8 \mathrm{~h}$ to ensure a stable temperature within the specimen. 


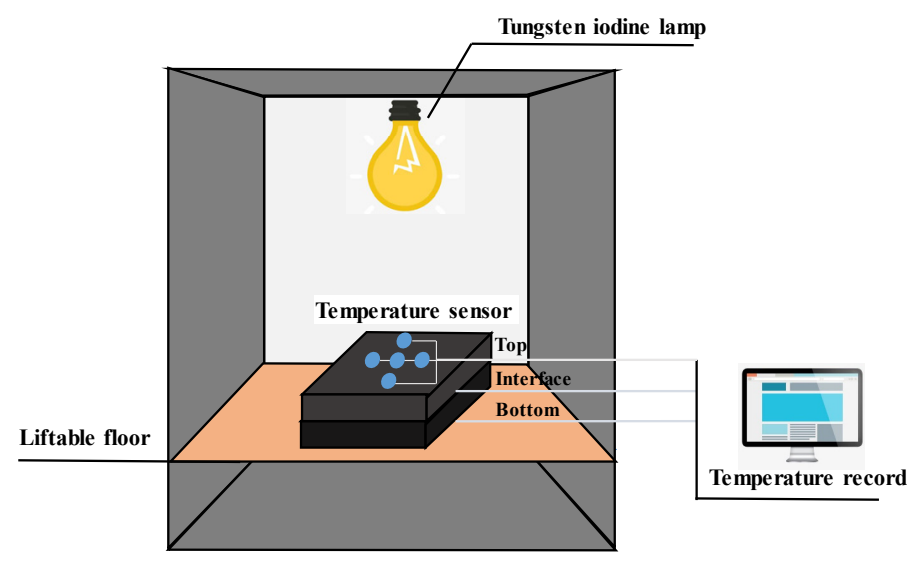

Figure 5. Schematic diagram of sunshine simulator.

\subsection{Numerical Model}

To assess the influence of CASMAs on the thermal field and the rutting resistance of cooling asphalt pavement, a finite element model was established to analyze the temperature changing law of asphalt pavement structure with CASMAs. Based on the result, further simulation of permanent deformation under the impact of thermal field and wheel load was conducted.

\subsubsection{Theoretical Background}

Due to exposure to the outdoor environment, the temperature distribution of asphalt pavement presents continuous spatiotemporal variation with periodic climatic conditions. During this variation, the heat is conducted through the surface course, road base, and subgrade, leading to a complex and changeable thermal field. Therefore, the thermal field of the asphalt pavement structure under outdoor environmental conditions should be regarded as a transient thermal field. As for isotropic homogeneous materials, the unsteady heat conduction in the three-dimensional space follows the Fourier partial differential equation and energy conservation law [42]. In other words, the transient thermal field of asphalt pavement is governed by the differential equation as follows:

$$
\rho \cdot c \frac{\partial T}{\partial t}-\lambda \cdot\left(\frac{\partial^{2} T}{\partial x^{2}}+\frac{\partial^{2} T}{\partial y^{2}}+\frac{\partial^{2} T}{\partial z^{2}}\right)-Q=0
$$

where $\rho$ is the density of pavement material $\left(\mathrm{kg} / \mathrm{m}^{3}\right) ; c$ is the specific heat of pavement material $\left(\mathrm{J} \cdot \mathrm{kg}^{-1} \cdot \mathrm{K}^{-1}\right) ; \lambda$ is the thermal conductivity of pavement material $\left(\mathrm{W} \cdot \mathrm{m}^{-1} \cdot \mathrm{K}^{-1}\right) ; x, y$, and $z$ are Cartesian coordinates; and $Q$ is the heat generated internally per unit volume, here $Q=0$.

Combined with the boundary condition of heat conduction, the temperature distribution of asphalt pavement can be obtained following the differential Equation (2). Based on the theory of heat conduction, the thermodynamic boundary conditions of pavement can mainly be classified into two types. Once the temperature of the pavement structure boundary is designated, the thermodynamic boundary condition can be regarded as the first type, namely the Dirichlet condition, which is defined as:

$$
T(x, y, z, t)=\bar{T}(t)
$$

where $\bar{T}(t)$ is the designated temperature of the pavement structure boundary $\left({ }^{\circ} \mathrm{C}\right)$.

Once the heat flux density at the boundary of the pavement structure is prescribed, the thermodynamic boundary condition can be regarded as the second type, namely the Neumann condition, which is defined as:

$$
\lambda\left(\frac{\partial T}{\partial x} n_{x}+\frac{\partial T}{\partial y} n_{y}+\frac{\partial T}{\partial z} n_{z}\right)=\bar{q}(t)
$$


where $n_{x}, n_{y}$, and $n_{z}$ are direction cosines of the outward normal to the pavement surfaces, respectively, and $\bar{q}(t)$ is the prescribed heat flux density at the pavement structure boundary $\left(\mathrm{W} / \mathrm{m}^{2}\right)$. As for asphalt pavement exposed to the outdoor environment, the heat flux density $\bar{q}(t)$ at the pavement surface includes solar radiation $q_{s}$, convection heat transfer $q_{c}$, and thermal irradiation $q_{r}$ [43], as presented in Figure 6.

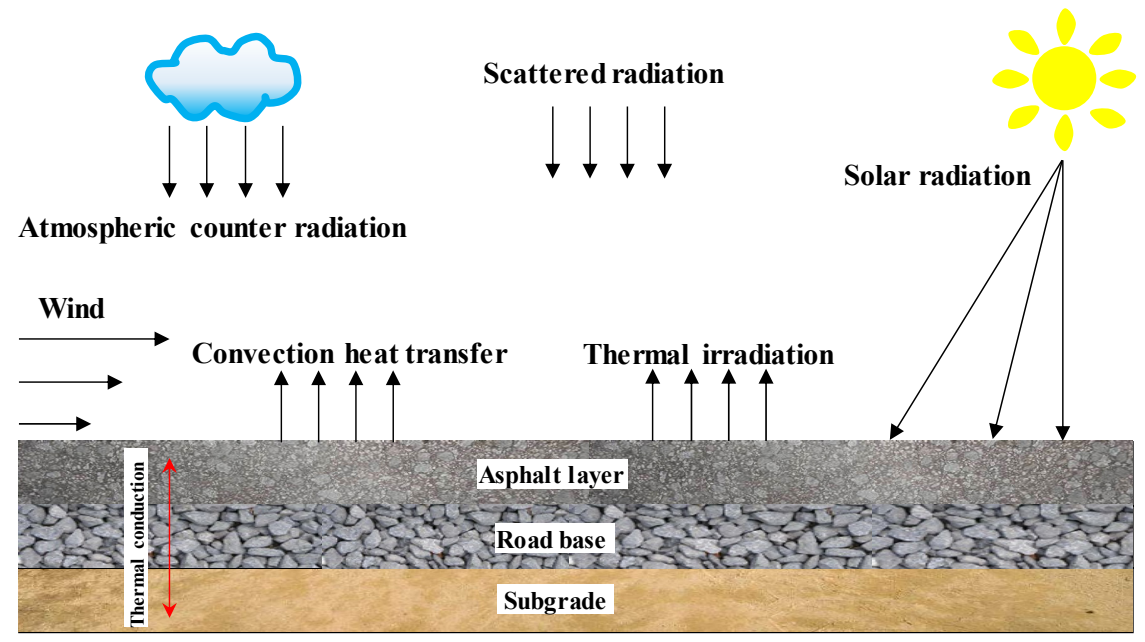

Figure 6. Environmental conditions of asphalt pavement structure.

Solar radiation consists of scattered radiation and direct solar radiation, and the daily variation of solar radiation $q_{s}$ can be calculated following Equation (5) [44]:

$$
q_{s}= \begin{cases}0, & 0 \leq t<12-c / 2 \\ q_{0} \cos m \omega(t-12), & 12-c / 2 \leq t \leq 12+c / 2 \\ 0, & 12+c / 2<t \leq 24\end{cases}
$$

where $q_{0}$ is the maximum solar radiation at noon, $q_{0}=0.131 \mathrm{~m} \mathrm{Q} ; Q$ is the total daily solar radiation $\left(\mathrm{J} / \mathrm{m}^{2}\right) ; c$ is the daily effective sunshine hours $(\mathrm{h}) ; m$ is the distribution coefficient for solar radiation, $m$ $=12 / c ; \omega$ is the angular frequency, $\omega=2 \pi / 24$ (rad).

During convective heat transfer, heat exchange occurs between the asphalt pavement surface and adjacent air. Based on Newton's convection cooling law [45], the convection heat transfer $q_{c}$ can be calculated as:

$$
q_{c}=\beta \cdot A \cdot\left(T-T_{a}\right)
$$

where $\beta$ is the convection heat transfer coefficient $\left(\mathrm{W} \cdot \mathrm{m}^{-2} \cdot \mathrm{K}^{-1}\right) ; \beta=3.0 v+5.6$, in which $v$ is the wind speed $\left(\mathrm{m} \cdot \mathrm{s}^{-1}\right)$; $\mathrm{A}$ is the contact area $\left(\mathrm{m}^{2}\right)$; and $T_{a}$ is the air temperature $\left({ }^{\circ} \mathrm{C}\right)$.

While absorbing the radiation emitted from the environment, the asphalt pavement also radiates energy in the form of long-wave radiation. According to the Stefan-Boltzmann law [43], the thermal irradiation $q_{r}$ between the pavement surface and adjacent air can be defined by using the following formula:

$$
q_{r}=C_{s} \times e \times\left[\left(T-T^{*}\right)^{4}-\left(T_{a}-T^{*}\right)\right]
$$

where $e$ is the emissivity coefficient of the asphalt pavement surface, here $e=0.81 ; C_{s}$ is the Stefan-Boltzmann constant, $C_{s}=5.6697 \times 10^{-8} \mathrm{~W} \mathrm{~m}^{-2} \mathrm{~K}^{-4}$; and $T^{*}$ is the absolute zero degree, $T^{*}=-273^{\circ} \mathrm{C}$. 
Combined with Equations (5)-(7), the temperature boundary condition of the asphalt pavement could be calculated according to Equation (4):

$$
\lambda\left(\frac{\partial T}{\partial x} n_{x}+\frac{\partial T}{\partial y} n_{y}+\frac{\partial T}{\partial z} n_{z}\right)=q_{s}+\beta \cdot A \cdot\left(T-T_{a}\right)+C_{s} \times e \times\left[\left(T+T^{*}\right)^{4}-\left(T_{a}+T^{*}\right)\right]
$$

\subsubsection{FE Model for Pavement Thermal Field and Mechanical Response Analysis}

An ordinary urban asphalt pavement structure used in Kunshan city in Jiangsu province was considered in this study, as shown in Figure 7a. The asphalt layers consisted of a surface course $(4 \mathrm{~cm}$ SMA-13), an intermediate course (6 $\mathrm{cm}$ AC-20), and a base course ( $8 \mathrm{~cm}$ AC-25). A drilled specimen from each asphalt layer was tested for thermophysical properties through the hot disc method test. In contrast, the thermophysical properties of the road base and subgrade were obtained from the literature [46]. Here, road base consisted of a cement stabilized macadam layer ( $35 \mathrm{~cm} \mathrm{CSM}$ ) and graded gravel (20 cm GG). The corresponding thermal parameters are listed in Table 5.

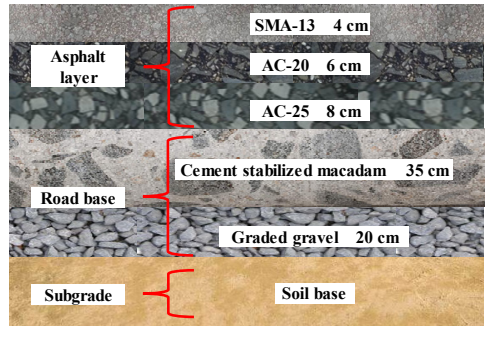

(a)

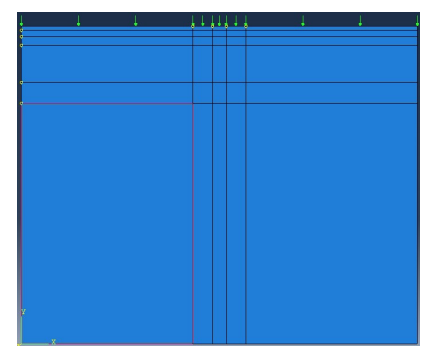

(b)

Figure 7. Ordinary asphalt pavement structure in China: (a) Asphalt pavement structure; (b) 2D FE model.

Table 5. Thermal parameters.

\begin{tabular}{ccccccc}
\hline Item & SMA-13 & AC-20C & AC-25C & CSM & Graded Gravel & Soil Base \\
\hline Thermal conductivity $/ \mathrm{W} \mathrm{m}^{-1} \cdot \mathrm{K}^{-1}$ & 1.302 & 1.070 & 1.000 & 1.560 & 1.200 & 1.560 \\
Density $/ \mathrm{kg} \mathrm{m}^{-3}$ & 2520 & 2412 & 2333 & 2200 & 2000 & 1800 \\
Specific heat/ $/ \mathrm{kg}^{-1} \mathrm{~K}^{-1}$ & 812.6 & 852.1 & 801.4 & 911.7 & 900.0 & 1040.0 \\
Solar radiation absorption rate & & & & 0.90 & & \\
Emissivity coefficient & & & & 0.81 & & \\
\hline
\end{tabular}

The time hardening creep model was applied to describe the viscoelastic behavior of asphalt mixture under repeated wheel load. The time hardening creep model is shown in Table 6.

Table 6. Creep parameters of surface course.

\begin{tabular}{ccccccc}
\hline $\begin{array}{c}\text { Time Hardening } \\
\text { Creep Model }\end{array}$ & $\begin{array}{c}\text { Asphalt } \\
\text { Mixture Type }\end{array}$ & Temperature $/{ }^{\circ} \mathbf{C}$ & $\boldsymbol{A}$ & $\boldsymbol{n}$ & $\boldsymbol{m}$ & $\boldsymbol{R}^{\mathbf{2}}$ \\
\hline & & 20 & $6.536 \times 10^{-11}$ & 0.937 & -0.592 & 0.9326 \\
& SMA-13-0\% & 30 & $3.325 \times 10^{-9}$ & 0.862 & -0.587 & 0.9459 \\
& & 40 & $1.446 \times 10^{-8}$ & 0.792 & -0.577 & 0.9420 \\
$\dot{\varepsilon}_{c r}=A q^{n} t^{m}$ & & 60 & $1.390 \times 10^{-6}$ & 0.414 & -0.525 & 0.9244 \\
& & 20 & $1.464 \times 10^{-5}$ & 0.336 & -0.502 & 0.9049 \\
& CASMA-13-40\% & 30 & $2.029 \times 10^{-11}$ & 0.909 & -0.784 & 0.9855 \\
& & 40 & $3.267 \times 10^{-8}$ & 0.852 & -0.778 & 0.9860 \\
& & 50 & $1.598 \times 10^{-6}$ & 0.396 & -0.668 & 0.9693 \\
& & 60 & $1.698 \times 10^{-5}$ & 0.341 & -0.611 & 0.9470 \\
& & & & & & 0.9523 \\
\hline
\end{tabular}


The model parameters of $A, n$, and $m$ for asphalt mixture were used as inputs in the FE model. Because of the temperature dependency of asphalt mixture, the tri-axial repeated loading creep test and compressive rebound modulus test were both conducted at $20,30,40,50$, and $60{ }^{\circ} \mathrm{C}$, respectively. On the other hand, the materials used in the road base and subgrade were regarded as linear elastic. The viscoelastic parameters of SMA and CASMAs are listed in Table 6 as an example.

A two-dimensional finite element model created by the finite element software ABAQUS 6.11 was used to calculate the rutting deformation of asphalt pavement under the impacts of repeated wheel load and thermal field. Figure $7 \mathrm{~b}$ shows the 2D FE model of the pavement structure. In the model, all the layers were modeled by the shell element, and the tied contact was set between the layers assuming that the deformation of different layers was continuous. The boundary condition of the model was constrained for deformation in all directions. According to the analysis of size sensitivity, the width and depth of the asphalt pavement model were set 3.75 and $3 \mathrm{~m}$, respectively. The transient thermal field of asphalt pavement was first simulated considering solar radiation, convective heat transfer, thermal irradiation, and conduction between pavement layers. Based on the temperature field of asphalt pavement, the stone mastic asphalt's creep parameters in the 2D FE model were modified, and cumulative rutting deformation of asphalt pavement caused by the repeated wheel load was then calculated.

The applied wheel load was a $100 \mathrm{kN}$ dual-tire assembly with a speed of $60 \mathrm{~km} / \mathrm{h}$. Constant static load was applied in the 2D FE model to simulate the repeated dynamic wheel load. Thus, the corresponding number of passes of the repeated dynamic load could be converted into the cumulative time of constant static load. The tire-pavement contact stress was simplified as an equivalent dual-rectangular uniform pressure of $0.7 \mathrm{MPa}$. More details on constant static load and dual-rectangular uniform stress can be found in one of the authors' previous publications [47].

\subsubsection{Model Verification}

A field experiment was carried out to monitor the thermal field of asphalt layers in pavement structure through embedded thermocouples. The total daily solar radiation measured was $22.3 \times 10^{6}$ $\mathrm{J} / \mathrm{m}^{2}$, the average wind speed was $2.4 \mathrm{~m} \cdot \mathrm{s}^{-1}$, and the daily effective sunshine was $11.3 \mathrm{~h}$. The monitoring and simulated temperatures of asphalt pavement at different depths are shown in Figure 8.

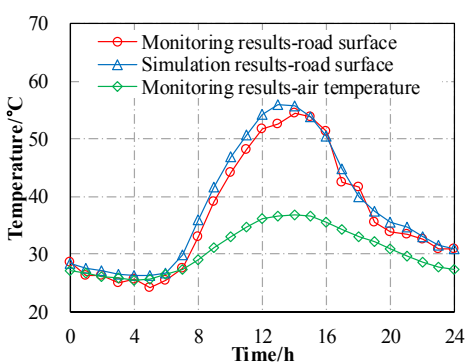

(a)

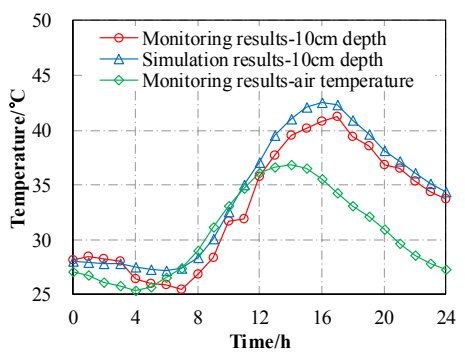

(c)

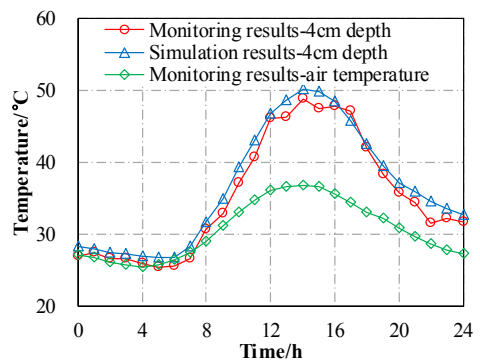

(b)

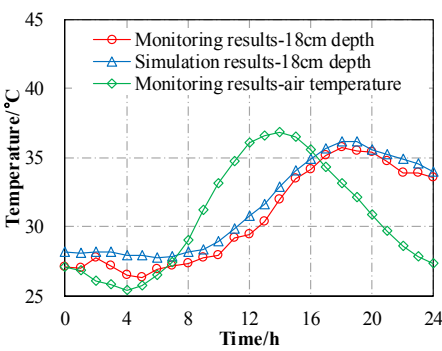

(d)

Figure 8. Simulation results compared with the monitoring results: (a) Road surface; (b) $4 \mathrm{~cm}$ depth; (c) $10 \mathrm{~cm}$ depth; (d) $18 \mathrm{~cm}$ depth. 
It can be found from Figure 8 that most of the simulated pavement temperatures were higher than that of the monitoring values, which means that the calculation from the FE model was conservative. This observation is because the heat dissipated caused by water evaporation was not considered in the FE model. On the other hand, the maximum temperature difference between the calculated value and the monitoring value was $3.4^{\circ} \mathrm{C}$, and the corresponding error was about $6.9 \%$, which indicates that the 2D FE model in this study could be used to predict the thermal field of the asphalt pavement structure.

The rutting deformation of the asphalt pavement in the reference was calculated through the parameters recorded [46]. The subsidence part of the simulated cumulative rutting deformation was compared with the instrumentation measurements in the experimental pavement, as presented in Figure 9. The result shows that the simulated rutting deformation matches well with field data recorded in the reference, which indicates that this FE model is reliable for the deformation analysis of asphalt pavement structure.

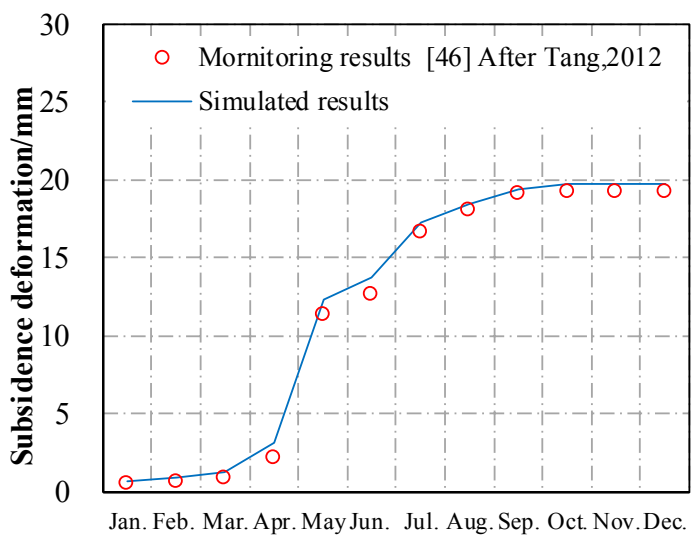

Figure 9. Monitoring and simulated cumulative rutting deformation subsidence.

\section{Results and Discussion}

\subsection{Experimental Results}

Implemented as the surface course of cooling asphalt pavement, CASMAs should not only meet the conventional technical requirements of asphalt pavement but also have good thermal insulation performance. Table 7 summarizes the test results of CASMAs and SMA.

Table 7. Test results of stone mastic asphalt.

\begin{tabular}{|c|c|c|c|c|c|c|c|c|}
\hline \multirow{2}{*}{ Index } & \multirow{2}{*}{ Temperature/ $/{ }^{\circ} \mathrm{C}$} & \multirow{2}{*}{ SMA-13 } & \multicolumn{5}{|c|}{ CASMA-13 } & \multirow{2}{*}{ Criterion } \\
\hline & & & $10 \%$ & $20 \%$ & $30 \%$ & $40 \%$ & $50 \%$ & \\
\hline Dynamic stability/pass $\cdot \mathrm{mm}^{-1}$ & 60 & 5364 & 4652 & 4531 & 4181 & 3524 & 2036 & $\geq 3000$ \\
\hline TSR $/ \%$ & 15 & 90.6 & 85.7 & 83.5 & 83.2 & 80.2 & 74.8 & $\geq 75$ \\
\hline Failure bending strain $/ \mu \varepsilon$ & -10 & 3024 & 2751 & 2730 & 2698 & 2703 & 2583 & $\geq 2500$ \\
\hline $\begin{array}{l}\text { Thermal } \\
\text { conductivity } / \mathrm{W} \cdot \mathrm{m}^{-1} \cdot \mathrm{K}^{-1}\end{array}$ & & 1.302 & 1.035 & 0.831 & 0.716 & 0.611 & 0.570 & \\
\hline Thermal diffusivity $/ 10^{-7} \mathrm{~m}^{2} \cdot \mathrm{s}^{-1}$ & 20 & 6.358 & 4.864 & 3.642 & 3.010 & 2.569 & 2.341 & - \\
\hline Specific heat $/ J \cdot \mathrm{kg}^{-1} \cdot \mathrm{K}^{-1}$ & & 812 & 982 & 1093 & 1168 & 1269 & 1324 & \\
\hline BPN & 25 & 73 & 70 & 72 & 70 & 71 & 72 & $\geq 45$ \\
\hline Mean texture depth/mm & 25 & 1.04 & 0.88 & 0.98 & 0.95 & 0.94 & 1.05 & $\geq 0.8$ \\
\hline
\end{tabular}

As shown in Table 7, the dynamic stability of the stone mastic asphalt decreased as the content of ceramic waste aggregate increased, indicating that the more CA, the more significant rutting deformation of the stone mastic asphalt. Additionally, the largest decreasing amplitude of dynamic stability for the stone mastic asphalt was found within a CA content range of $40 \%$ to $50 \%$. The lowest dynamic stability value of CASMAs was $62 \%$ smaller than that of SMA-13, which failed to meet 
the technical requirement of over 3000 pass $\mathrm{mm}^{-1}$. This phenomenon may be attributed to the higher crushing value and flat and elongated particle content for ceramic waste aggregate. Therefore, the content of ceramic waste aggregate used in stone mastic asphalt should not exceed $40 \%$ in terms of rutting resistance.

As for moisture susceptibility, the TSRs of all stone mastic asphalt, except for CASMA-13 containing $50 \%$ CA, met the criteria requirement $(\geq 75 \%)$. The worse TSR of CASMAs was about $15 \%$ smaller than that of SMA. This phenomenon is mainly due to the poor adhesion between ceramic waste aggregate and asphalt. It could be concluded that increasing the CA content goes against the freeze-thaw moisture damage resistance of stone mastic asphalt.

Failure bending strain is an important index for evaluating the cracking resistance performance of stone mastic asphalt. As found, the maximum bending strain of SMA-13 was higher than that of CASMAs. The smallest bending strain of CASMAs (for the case of $50 \%$ CA) was $441 \mu \varepsilon$ lower than that of SMA-13. In the three-point bending beam test, the bending strength of CASMAs ranged from 11.73 to $12.86 \mathrm{MPa}$, while the bending strength of SMA-13 was 13.26 MPa. All these observations indicate that the cracking resistance performance of stone mastic asphalt decreases with the increase of CA content.

With the increase of ceramic waste aggregate in stone mastic asphalt, thermal conductivity and thermal diffusivity gradually decreased, while the specific heat increased. Incorporation of $10 \% \mathrm{CA}$ into stone mastic asphalt could result in a $23.5 \%$ reduction of thermal conductivity, a $20.9 \%$ reduction of thermal diffusivity, and a $20.9 \%$ increment of specific heat. On the other hand, the incorporation of $50 \%$ CA into stone mastic asphalt made little difference compared with that of $40 \% \mathrm{CA}$, revealing that the improving effect of ceramic waste aggregate on thermal insulation slowed down once the content exceeded $40 \%$. As a whole, it could be inferred that CASMAs can be an attractive material for the thermal insulation of asphalt pavement.

The results of the BPN test and MTD test illustrate that the conventional SMA-13 and the stone mastic asphalt containing CA can both meet the criteria of SMA's skid resistance, and could provide friction as a surface course of asphalt pavement.

Figure 10 presents the fatigue resistance performance of stone mastic asphalt with different contents of ceramic waste aggregate. As the stress ratio increased from 0.3 to 0.6 , the fatigue life of stone mastic asphalt decreased sharply. When subjected to the same stress ratio, the tested fatigue life of SMA-13 had no obvious difference from that of the CASMAs, revealing that the incorporation of ceramic waste aggregate may not harm the fatigue resistance performance of stone mastic asphalt.

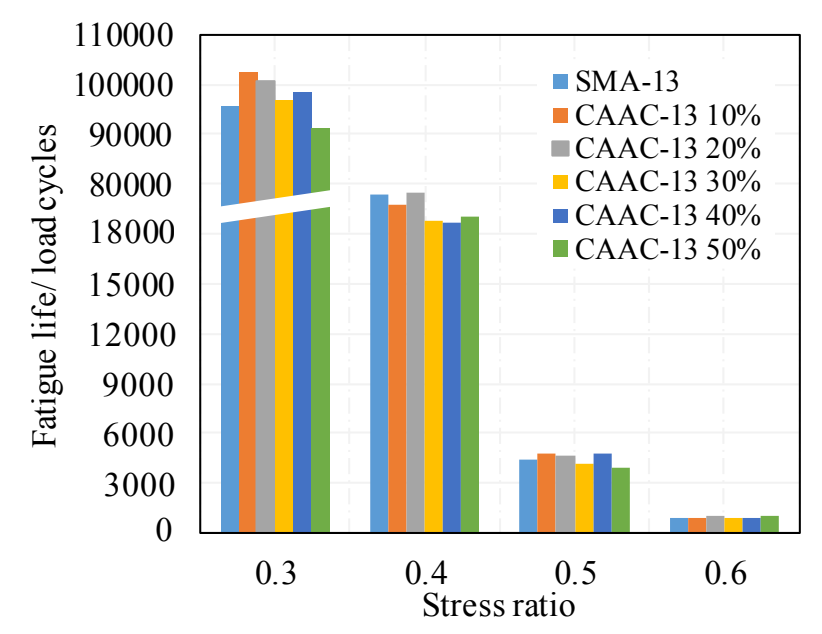

Figure 10. Fatigue life of beams at different stress ratios.

Two-way ANOVA was conducted for statistical analysis of the fatigue resistance performance of stone mastic asphalt with different CA contents at a 95\% confidence level. The results are listed 
in Table 8. Various stress ratios significantly affect fatigue life in the statistics, but the contents of ceramic waste aggregate have no significant effect on fatigue life in the statistics. Therefore, it could be concluded that CASMAs could meet the requirements for resisting fatigue damage at mid-temperature.

Table 8. Two-way ANOVA results for fatigue test.

\begin{tabular}{cccccc}
\hline Object & Factor & DF & F-Value & $p$-Value & Significance \\
\hline \multirow{2}{*}{ Fatigue life } & Stress ratio & 3 & 2568.85 & $<0.001$ & $* * *$ \\
& CA content & 5 & 1.800 & 0.173 & - \\
\hline & $* * *$ presents high significance; - presents no significance.
\end{tabular}

The temperatures at the surface, interface, and bottom of the double-layer slab specimen (CASMA-13 + AC-20) were recorded during the indoor thermal insulation performance test, and the results are shown in Table 9.

Table 9. Results of indoor thermal insulation performance test.

\begin{tabular}{ccccccc}
\hline Index & & \multicolumn{5}{c}{ CASMA-13 } \\
\cline { 3 - 7 } & SMA-13 & $\mathbf{1 0 \%}$ & $\mathbf{2 0 \%}$ & $\mathbf{3 0 \%}$ & $\mathbf{4 0 \%}$ & $\mathbf{5 0 \%}$ \\
\hline Temperature of compound specimen surface $/{ }^{\circ} \mathrm{C}$ & 68.5 & 68.9 & 69.1 & 69.6 & 70.7 & 70.9 \\
Temperature of compound specimen interface $/{ }^{\circ} \mathrm{C}$ & 66.1 & 63.1 & 61.4 & 60.5 & 60.3 & 59.7 \\
Temperature of compound specimen bottom $/{ }^{\circ} \mathrm{C}$ & 51.6 & 46.9 & 45.3 & 43.7 & 43.2 & 42.5 \\
Temperature difference between surface and interface $/{ }^{\circ} \mathrm{C}$ & 2.4 & 5.8 & 7.7 & 9.1 & 10.4 & 11.2 \\
Temperature difference between surface and bottom $/{ }^{\circ} \mathrm{C}$ & 16.9 & 22.0 & 23.8 & 25.9 & 27.5 & 28.4 \\
\hline
\end{tabular}

It can be found from Table 9 that the surface temperature gradually increased with the increase of ceramic waste aggregate in CASMAs. This phenomenon is due to the more significant heat absorption of CASMA-13 caused by higher optimal asphalt content. In contrast, the interface temperature and bottom temperature both decreased as the ceramic waste aggregate increased. Simultaneously, the surface-interface temperature gap and surface-bottom temperature gap increased. This was because the incorporation of ceramic waste aggregate could lower the thermal conductivity and thermal diffusivity of the surface course, and helped to weaken the heat conduction between layers. For example, the surface-interface temperature gap of CASMA-13 (50\% CA) + AC-20 was $8.8{ }^{\circ} \mathrm{C}$ larger than that of SMA-13 + AC-20. Similarly, the surface-bottom temperature gap of CASMA-13 (50\% CA) + AC-20 was $11.5^{\circ} \mathrm{C}$ larger than that of SMA-13 + AC-20. Although the temperature gap here maybe deviated from the field's actual situation, it could be inferred that asphalt pavement with a CASMAs surface course has better performance in terms of the cooling effect than that with conventional SMA.

\subsection{Numerical Results}

\subsubsection{Thermal Effect Analysis of Cooling Asphalt Pavement}

Based on the validated thermal field model, the thermophysical inputs of surface course material (CASMAs) were modified to analyze the temperature distributions of cooling asphalt pavement with different CA contents. The thermal simulation results for asphalt layers in the cooling asphalt pavement are given in Figure 11.

When CASMAs were implemented as a surface course of the pavement structure, the maximum temperature of the road surface increased with the increase of CA content, while the maximum temperatures within the asphalt pavement gradually decreased with the rise of CA content. The reason might be that ceramic waste aggregate could reduce thermal conductivity, resulting in poorer heat conduction between the cooling asphalt pavement layers. More heat was accumulated within the surface course, and the amount of heat transferred downward become smaller. Thus, temperatures at the intermediate and base course of asphalt layers dropped. Taking the cooling asphalt pavement 
containing CASMA-13 (50\% CA) as an example, the maximum temperatures at depths of $4 \mathrm{~cm}, 10 \mathrm{~cm}$, and $18 \mathrm{~cm}$ were $5.5^{\circ} \mathrm{C}, 3.2^{\circ} \mathrm{C}$, and $1.6^{\circ} \mathrm{C}$ lower than that of conventional asphalt pavement without a CASMA thermal insulation layer. On the other hand, the amplitude of thermal conductivity reduction got smaller when the incorporation of ceramic waste aggregate exceeded $40 \%$, accompanied by a smaller amplitude of temperature reduction within the asphalt pavement, as shown in Figure 11. Combining the test results of road performance and the simulation results for temperature reduction, the content of ceramic waste aggregate used in stone mastic asphalt was recommended as $40 \%$. As a result, the rutting deformation of the cooling pavement including a CASMA-13 (40\% CA) surface course was further investigated and is described in the next section.

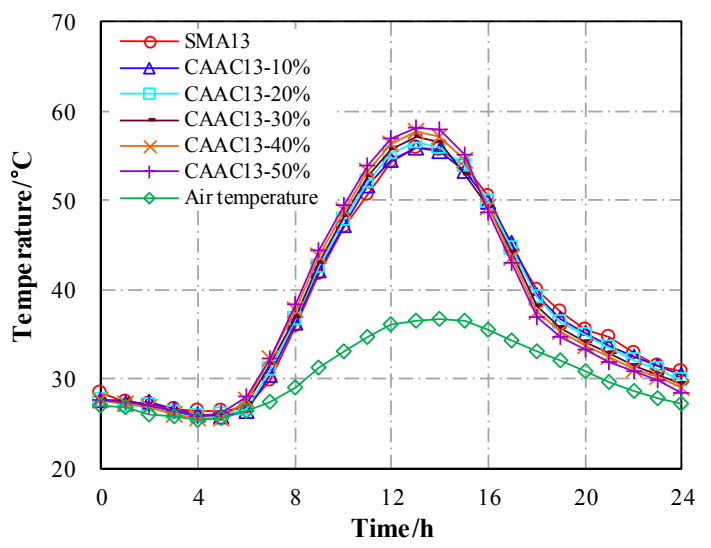

(a)

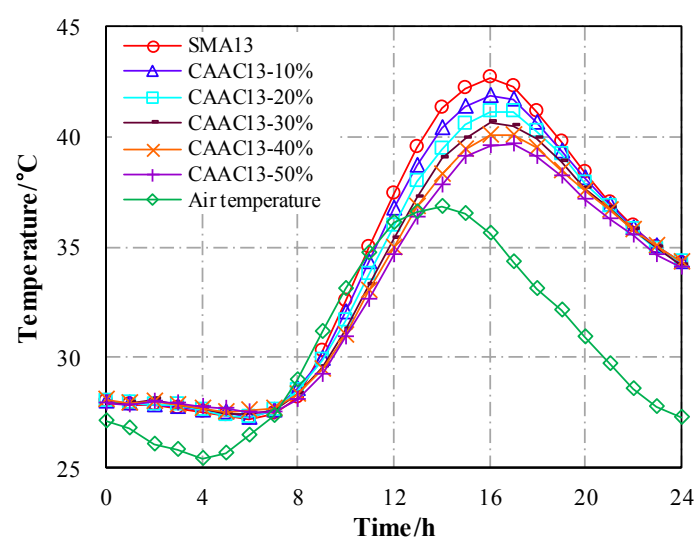

(c)

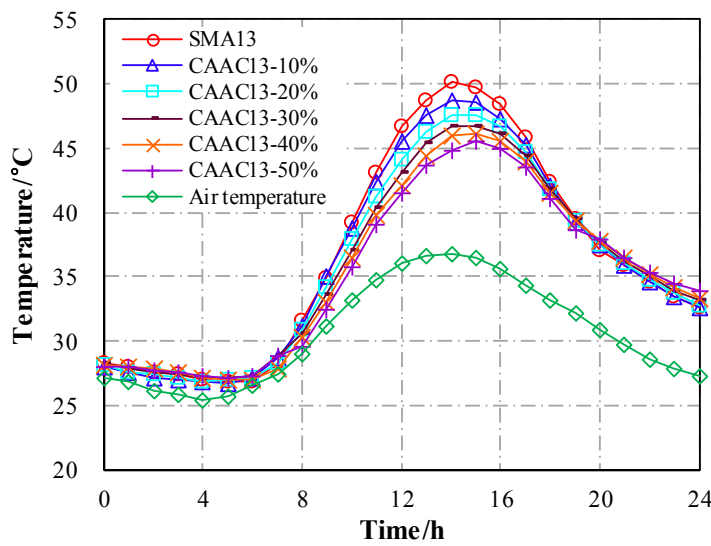

(b)

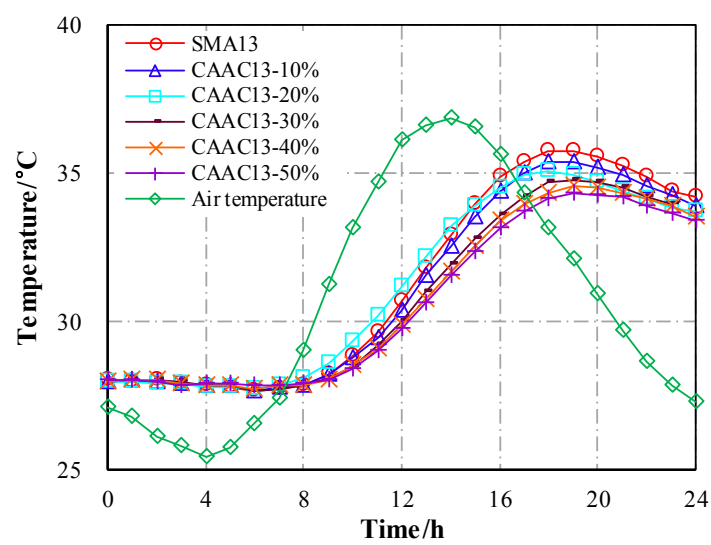

(d)

Figure 11. Effect of CASMA-13 on the temperature evolution of asphalt layers: (a) Road surface; (b) $4 \mathrm{~cm}$ depth; (c) $10 \mathrm{~cm}$ depth; (d) $18 \mathrm{~cm}$ depth.

\subsubsection{Rutting Deformation Analysis of Cooling Asphalt Pavement}

The viscoelasticity of asphalt mixture is very sensitive to temperature. It is necessary to introduce the initial thermal field into each analysis step when simulating the rutting deformation of asphalt pavement. The simulated temperature distributions of cooling asphalt pavement and conventional asphalt pavement at different times are shown in Figure 12.

Based on the validated FE model, the rutting deformations of different pavement structures under repeated wheel load and environmental impact were analyzed. Conventional pavement structure (without a thermal insulation layer) was used as a reference group for the cooling asphalt 
pavement (with a CASMA thermal insulation layer). The corresponding simulated results of permanent deformation after 500,000 passes of axle loads are shown in Figures 13 and 14.

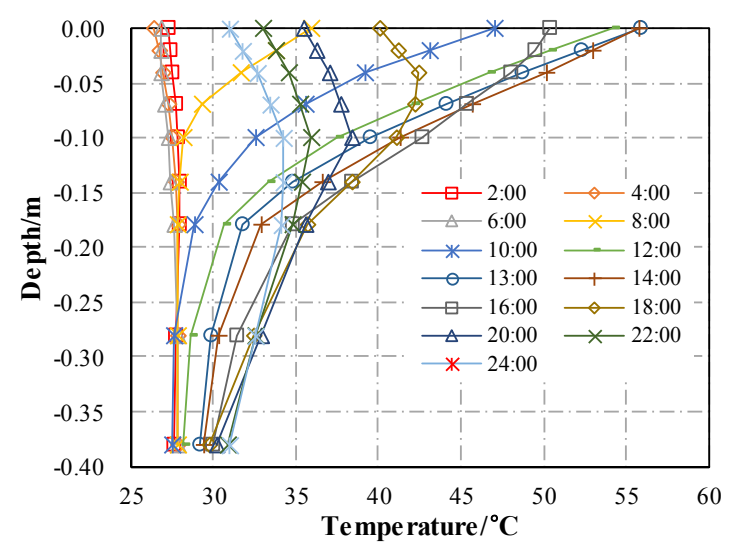

(a)

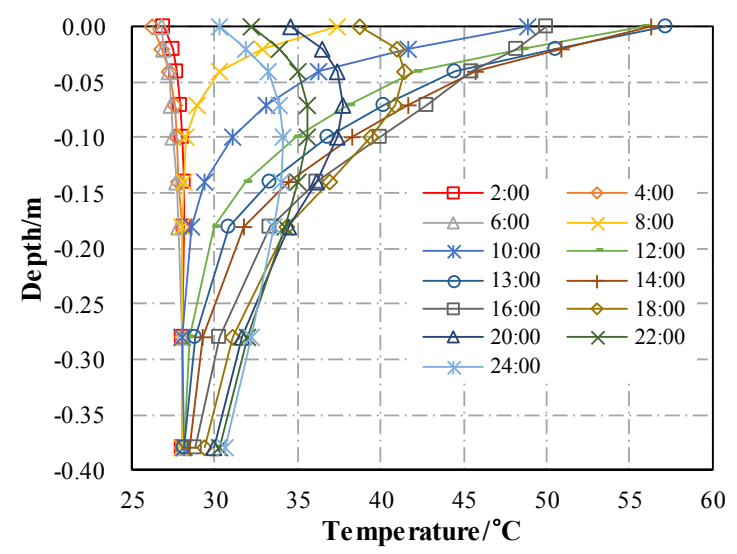

(b)

Figure 12. Asphalt pavement temperature and depth at different times: (a) Conventional asphalt pavement; (b) Cooling asphalt pavement with CASMA thermal insulation layer.

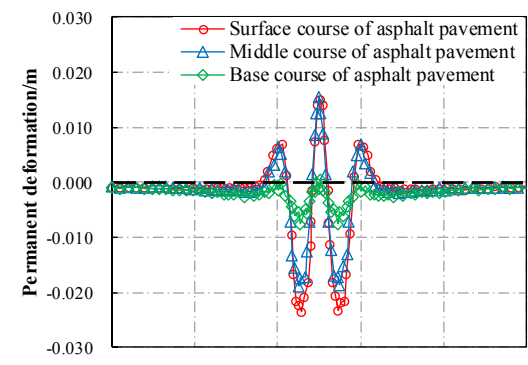

(a)

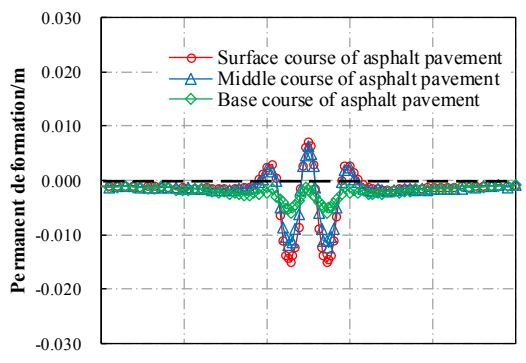

(b)

Figure 13. Distributions of permanent deformation at different depths: (a) Conventional asphalt pavement; (b) Cooling asphalt pavement with CASMA thermal insulation layer.

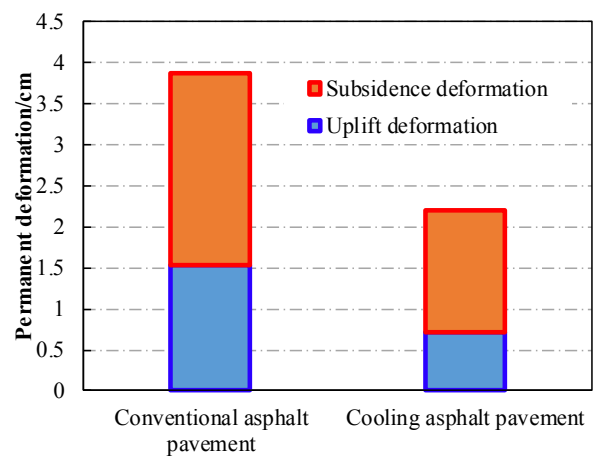

Figure 14. Rutting deformations of two different asphalt pavement structures.

When subjected to long-term repeated wheel load, each asphalt layer of the pavement suffered a visible rutting deformation. The maximum subsidence deformation occurred right below the center of the wheel load. Furthermore, uplift deformation also appeared adjacent to the wheel load due to the lateral flow of asphalt mixture. Since the conventional asphalt pavement absorbed more heat and transferred it faster to the lower layers, the temperature within this pavement was higher than that of the cooling asphalt pavement with the CASMA thermal insulation layer. A higher temperature could lead to a worse rutting resistance of asphalt mixture. As a result, the permanent rutting deformation of 
the cooling asphalt pavement $(2.12 \mathrm{~cm})$ was much smaller than that of conventional asphalt pavement $(3.88 \mathrm{~cm})$, and the corresponding reduction of rutting deformation was $45.36 \%$. Although the simulated rutting deformation here maybe deviated from the field's actual situation, it could be inferred that the cooling asphalt pavement with a CASMA thermal insulation layer had better performance in rutting resistance than that of the conventional structure.

\section{Conclusions}

This paper investigated the feasibility of utilizing ceramic waste as the coarse aggregate in cooling asphalt pavement. Stone mastic asphalt (SMA) containing 10\%, 20\%, 30\%, 40\%, and $50 \%$ coarse ceramic waste aggregate (CASMAs) was first designed using the Marshall method. Afterward, the road performance and thermal insulation performance of the five different CASMAs were assessed by a comprehensive lab test, including a wheel rutting test, moisture susceptibility test, bending beam test, fatigue beam test, and indoor thermal insulation test. Finally, a 2D finite-element model was developed to investigate the transient thermal field and rutting deformation response of the cooling asphalt pavement with CASMAs. The following conclusions can be drawn based on the analysis:

(1) As the incorporation of ceramic waste aggregate increased, the stone mastic asphalt's optimum asphalt content and flow value gradually increased, while the stone mastic asphalt's Marshall stability and density gradually decreased.

(2) The CASMAs designed in this paper experienced degradation of some road performances as the content of ceramic waste aggregate increased. The smallest dynamic stability of CASMAs was about $62 \%$ lower than that of conventional SMA. The smallest TSR value and failure bending strain of CASMAs were about $15 \%$ smaller than those of SMA. In contrast, SMA and CASMAs have no significant difference in fatigue life, and both can provide friction as a surface course of cooling asphalt pavement.

(3) The thermal conductivity of conventional SMA was 1.25-2.28 times that of CASMAs, and CASMAs could be an attractive material for the thermal insulation layer of cooling asphalt pavement. The indoor thermal insulation analysis confirmed that CASMAs had better thermal insulation performance than SMA. The best cooling effect was an $8.8^{\circ} \mathrm{C}$ reduction in temperature at the interface, and an $11.5^{\circ} \mathrm{C}$ reduction in temperature at the bottom, respectively.

(4) When CASMAs were implemented as a surface course in the thermal field simulation model, the pavement surface temperature increased, while the temperature within the pavement decreased. Combining the test results of road performance and thermal simulation results, the optimal content of ceramic waste aggregate in stone mastic asphalt was recommended as $40 \%$.

(5) When subjected to repeated traffic load outdoors, the permanent rutting deformation of cooling asphalt pavement was $45.36 \%$ smaller than that of conventional asphalt pavement, indicating that the cooling asphalt pavement with CASMA thermal insulation layer had a better anti-rutting performance.

Author Contributions: Conceptualization, Q.H. and Z.Q.; methodology, Q.H., and Z.Q.; formal analysis, Q.H. and J.H.; data curation, Q.H. and D.Z.; writing — original draft preparation, Q.H.; writing—review and editing, J.H. All authors have read and agreed to the published version of the manuscript.

Funding: This research was funded by the National Natural Science Foundation of China (Nos. 51678146 and 51708113), National Key R\&D Program of China (Nos. 2018YFB1600300 and 2018YFB1600304), and Natural Science Foundation of Jiangsu Province (Nos. BK20170671).

Conflicts of Interest: The authors declare no conflict of interest.

\section{References}

1. Majidifard, H.; Adu-Gyamfi, Y.; Buttlar, W.G. Deep machine learning approach to develop a new asphalt pavement condition index. Constr. Build. Mater. 2020, 247. [CrossRef] 
2. Akbari, H.; Matthews, H.D. Global cooling updates: Reflective roofs and pavements. Energy Build. 2012, 55, 2-6. [CrossRef]

3. Mohajerani, A.; Bakaric, J.; Jeffrey-Bailey, T. The urban heat island effect, its causes, and mitigation, with reference to the thermal properties of asphalt concrete. J. Environ. Manag. 2017, 197, 522-538. [CrossRef] [PubMed]

4. Xiao, F.; Ma, D.; Wang, J.; Cai, D.; Lou, L.; Yuan, J. Impacts of high modulus agent and anti-rutting agent on performances of airfield asphalt pavement. Constr. Build. Mater. 2019, 204. [CrossRef]

5. Garcia, V.M.; Barros, L.; Garibay, J.; Abdallah, I.; Nazarian, S. Effect of aggregate gradation on performance of asphalt concrete mixtures. J. Mater. Civ. Eng. 2020, 32. [CrossRef]

6. Azarhoosh, A.; Koohmishi, M. Investigation of the rutting potential of asphalt binder and mixture modified by styrene-ethylene/propylene-styrene nanocomposite. Constr. Build. Mater. 2020, 255. [CrossRef]

7. Cheng, X.; Liu, Y.; Ren, W.; Huang, K. Performance evaluation of asphalt rubber mixture with additives. Materials 2019, 12, 1200. [CrossRef]

8. $\quad$ Anting, N.; Din, M.F.M.; Iwao, K.; Ponraj, M.; Jungan, K.; Yong, L.Y.; Siang, A.J.L.M. Experimental evaluation of thermal performance of cool pavement material using waste tiles in tropical climate. Energy Build. 2017, 142, 211-219. [CrossRef]

9. Synnefa, A.; Karlessi, T.; Gaitani, N.; Santamouris, M.; Assimakopoulos, D.N.; Papakatsikas, C. Experimental testing of cool colored thin layer asphalt and estimation of its potential to improve the urban microclimate. Build. Environ. 2011, 46, 38-44. [CrossRef]

10. Jiang, Y.; Deng, C.; Chen, Z.; Tian, Y. Evaluation of the cooling effect and anti-rutting performance of thermally resistant and heat-reflective pavement. Int. J. Pavement. Eng. 2020, 21, 447-456. [CrossRef]

11. Wang, C.; Fu, Y.; Liu, L.; Li, T. Surface treatment optimization of thermal-resistant aggregate for pavement. J. Mater. Civ. Eng. 2020, 32. [CrossRef]

12. Ghaffar, S.H.; Burman, M.; Braimah, N. Pathways to circular construction: An integrated management of construction and demolition waste for resource recovery. J. Clean. Prod. 2020, 244. [CrossRef]

13. Mercante, I.T.; Bovea, M.D.; Ibanez-Fores, V.; Arena, A.P. Life cycle assessment of construction and demolition waste management systems: A spanish case study. Int. J. Life Cycle. Ass. 2012, 17, 232-241. [CrossRef]

14. Kisku, N.; Joshi, H.; Ansari, M.; Panda, S.K.; Nayak, S.; Dutta, S.C. A critical review and assessment for usage of recycled aggregate as sustainable construction material. Constr. Build. Mater. 2017, 131, 721-740. [CrossRef]

15. Soutsos, M.N.; Tang, K.; Millard, S.G. Concrete building blocks made with recycled demolition aggregate. Constr. Build. Mater. 2011, 25, 726-735. [CrossRef]

16. Hussein, A.A.; Jaya, R.P.; Yaacob, H.; Hassan, N.A.; Aletba, S.R.O.; Huseien, G.F.; Shaffie, E.; Hasan, M.R.M. Physical, chemical and morphology characterisation of nano ceramic powder as bitumen modification. Int. J. Pavement. Eng. 2019. [CrossRef]

17. Ratnasamy, M.; Elzarroug, A.E.; Bin, H.H.; Bt, Y.R. An initial investigation of the use of local industrial wastes and by-products as mineral fillers in stone mastic asphalt pavements. J. Eng. Appl. Sci. 2009, 4, 54-63.

18. Van de Ven, M.F.; Molenaar, A.A.; Poot, M.R. Asphalt mixtures with waste materials: Possibilities and constraints. In Proceedings of the Conference on Asphalt Pavements for Southern Africa, KwaZulu-Natal, South Africa, 1 September 2010-31 August 2011.

19. Silvestre, R.; Medel, E.; Garcia, A.; Navas, J. Using ceramic wastes from tile industry as a partial substitute of natural aggregates in hot mix asphalt binder courses. Constr. Build. Mater. 2013, 45, 115-122. [CrossRef]

20. BS 812-110. Methods for Determination of Aggregate Crushing Value (acv); British Standard: London, UK, 1990.

21. ASTM C131. Standard Test Method for Resistance to Degradation of Small-Size Coarse Aggregate by Abrasion and Impact in the Los Angeles Machine; American Standard for Testing and Materials: West Conshohocken, PA, USA, 2014.

22. ASTM D4791. Standard Test Method for Flat Particles, Elongated Particles, or Flat and Elongated Particles in Coarse Aggregate; American Standard for Testing and Materials: West Conshohocken, PA, USA, 2010.

23. ASTM C127. Standard Test Method for Relative Density (Specific Gravity) and Absorption of Coarse Aggregate; American Standard for Testing and Materials: West Conshohocken, PA, USA, 2015.

24. ASTM C128. Standard Test Method for Relative Density (Specific Gravity) and Absorption of Fine Aggregate; American Standard for Testing and Materials: West Conshohocken, PA, USA, 2015. 
25. ASTM D4318. Standard Test Methods for Liquid Limit, Plastic Limit, and Plasticity Index of Soils; American Standard for Testing and Materials: West Conshohocken, PA, USA, 2017.

26. ASTM D5. Standard Test Method for Penetration of Bituminous Materials; American Standard for Testing and Materials: West Conshohocken, PA, USA, 2013.

27. ASTM D36. Standard Test Method for Softening Point of Bitumen; American Standard for Testing and Materials: West Conshohocken, PA, USA, 2014.

28. ASTM D113. Standard Test Method for Ductility of Bituminous Materials; American Standard for Testing and Materials: West Conshohocken, PA, USA, 2007.

29. ASTM D2042. Standard Test Method for Solubility of Asphalt Materials in Trichloroethylene; American Standard for Testing and Materials: West Conshohocken, PA, USA, 2015.

30. ASTM D92. Standard Test Method for Flash and Fire Points by Cleveland Open Cup Tester; American Standard for Testing and Materials: West Conshohocken, PA, USA, 2016.

31. ASTM D2170. Standard Test Methods for Kinematic Viscosity of Asphalts (Bitumens); American Standard for Testing and Materials: West Conshohocken, PA, USA, 2010.

32. ASTM D1754. Standard Test Method for Effects of Heat and Air on Asphaltic Materials; American Standard for Testing and Materials: West Conshohocken, PA, USA, 2014.

33. JTG F40-2004. Technical Specification for Construction of Highway Asphalt Pavements; China Communications Press: Beijing, China, 2004.

34. JTG E20-2011. Standard Test Methods of Bitumen and Bituminous Mixtures for Highway Engineering; China Communications Press: Beijing, China, 2011.

35. ASTM WK49591. New Test Method for Determining Thermal Conductivity and Thermal Diffusivity Using the Transient Plane Source or Hot Disc Method; American Standard for Testing and Materials: West Conshohocken, PA, USA, 2015.

36. ASTM E303. Standard Test Method for Measuring Surface Frictional Properties Using the British Pendulum Tester; American Standard for Testing and Materials: West Conshohocken, PA, USA, 2013.

37. ASTM E965. Standard Test Method for Measuring Pavement Macrotexture Depth Using a Volumetric Technique; American Standard for Testing and Materials: West Conshohocken, PA, USA, 2006.

38. CEN-EN 12697-24. Bituminous Mixtures-Test Methods_Part 24: Resistance to Fatigue; European Committee for Standardization (CEN): Brussels, Belgium, 2018.

39. Al-Ajlan, S.A. Measurements of thermal properties of insulation materials by using transient plane source technique. Appl. Therm. Eng. 2006, 26, 2184-2191. [CrossRef]

40. Yang, Y.; Qian, Z.; Song, X. A pothole patching material for epoxy asphalt pavement on steel bridges: Fatigue test and numerical analysis. Constr. Build. Mater. 2015, 94, 299-305. [CrossRef]

41. Zhu, X.; Yu, Y.; Chen, L.; Zhang, D. Solar heat reflective coating for sidewalks considering cooling effect, anti-skid performance, and human comfort. J. Test. Eval. 2020, 48, 2028-2039. [CrossRef]

42. Ozbolt, J.; Bosnjak, J.; Periskic, G.; Sharma, A. 3D numerical analysis of reinforced concrete beams exposed to elevated temperature. Eng. Struct. 2014, 58, 166-174. [CrossRef]

43. Alonso-Estebanez, A.; Pascual-Munoz, P.; Luis Sampedro-Garcia, J.; Castro-Fresno, D. 3D numerical modelling and experimental validation of an asphalt solar collector. Appl. Therm. Eng. 2017, 126, 678-688. [CrossRef]

44. Sreedhar, S.; Biligiri, K.P. Development of pavement temperature predictive models using thermophysical properties to assess urban climates in the built environment. Sustain. Cities Soc. 2016, 22, 78-85. [CrossRef]

45. Kassem, H.; Chehab, G.; Saad, G. An fem-predictive tool for simulating the cooling characteristics of freshly paved asphalt concrete layers. Int. J. Pavement. Eng. 2015, 16, 157-167. [CrossRef]

46. Tang, J. Study on Climatic Regionalization and Temperature-Field Induced Rutting of Asphalt Pavement in Hainan Province; Central South University: Hunan, China, 2012.

47. Hu, J.; Qian, Z.; Yang, Y. High temperature properties of composite structure of gussasphalt + epoxy asphalt at bridge deck pavement. J. Central South Univ. 2015, 46, 1946-1952. [CrossRef]

(C) 2020 by the authors. Licensee MDPI, Basel, Switzerland. This article is an open access article distributed under the terms and conditions of the Creative Commons Attribution (CC BY) license (http://creativecommons.org/licenses/by/4.0/). 